\section{LAKE TANGANYIKA}

\section{By R. S. A. BEAUCHAMP}

$\mathrm{T}$ HE fauna of Lake Tanganyika has aroused great interest on account of its abundance of species, many of which are found nowhere else. The hydrological features of the Lake are no less remarkable and provide an explanation for the evolution of so many 'endemic' species. The Lake also offers exceptionally suitable material for studying a number of problems of general hydrobiological significance.

Lake Tanganyika, situated just south of the equator, is $650 \mathrm{~km}$. long, approximately $60 \mathrm{~km}$. wide and 1,500 metres deep. Probably the oldest lake in the world, it apparently has had no outlet until about 15,000 years ago, when it received the waters of the River Ruzizi. The Ruzizi drains Lake Kivu, which was formed as a result of voleanic upheavals. The Ruzizi is one of the larger inflows of Tanganyika, but even now the outlet from the Lake is small and intermittent. Evaporation accounts for ninety-five per cent of the total annual loss of water at the present time, yet the total salt concentration of the lake water is no more than 420 parts per million-an amount normal for lake waters. This may be explained by the facts that the inflows are of small volume and low salt content, and that rain falling directly on to the Lake accounts for two thirds of the total water supply.

The inflows amount annually in volume to little more than one two-thousandths of the volume of the Lake, and their average salt content, excluding the Ruzizi, is approximately 150 p.p.m. Thus before the entrance of the Ruzizi it would have taken approximately 2,000 years to increase the total salt content of the Lake by 150 p.p.m., if no biological precipitation of mineral matter occurred. But this occurs in all lakes; the bottom deposits contain the remains of plants and animals, the bodies of which are built up from minerals previously in solution. The precipitation of silica by diatoms and calcium by molluses clearly demonstrates the principle, which applies to some extent to all the mineral constituents of living bodies, but least of all to the very soluble salts of potassium and sodium. At the same time decomposition of the bottom deposits is gradually liberating these minerals; but in no lake does this process keep pace with the precipitation of organic matter, which is continually accumulating. In Tanganyika it appears that precipitation roughly balances both the small amounts of mineral matter brought in by the inflows, and the amount liberated by decomposition of the bottom deposits. This fact not only helps to explain the unexpectedly low concentration of salts in the Lake, but also the very unusual composition of the Lake water.

Table 1, col. 3, shows amounts, expressed as parts per million, of the constituents of the Lake water from samples collected from $700 \mathrm{~m}$. (the average middle depth of the Lake).

Table 2 shows the values for chloride and sulphate, and for magnesium and calcium expressed as ratios, and for comparison these ratios as they occur in the inflows and in sea water. It will be seen that the relative proportions in the Lake water are quite dissimilar from those in the inflows, but similar to those in sea water. The proportions in the inflows are, however, normal for fresh waters. It appears that biological processes have, over the very long period the Lake has existed, produced these alterations in
TABLE 1.

\begin{tabular}{|l|c|c|c|}
\hline & Inflows & $\begin{array}{c}\text { Tanganyika } \\
700 \mathrm{~m} .\end{array}$ & Factor \\
\hline Sodium & $25 \cdot 0$ p.p.m. & $64 \cdot 2 \mathrm{p.p.m}$. & $2 \cdot 57$ \\
Potassium & $9 \cdot 0$ & $33 \cdot 5$ & $3 \cdot 7$ \\
Lithium & $0 \cdot 28$ & $0 \cdot 8$ & $3 \cdot 0$ \\
Calcium & $19 \cdot 0$ & $15 \cdot 2$ & $0 \cdot 76$ \\
Magnesium & $17 \cdot 2$ & $43 \cdot 7$ & $2 \cdot 5$ \\
Iron & $<0 \cdot 1$ & $<0 \cdot 1$ & $1 \cdot 0$ \\
Aluminium & $0 \cdot 3$ & $0 \cdot 3$ & $1 \cdot 0$ \\
Chloride & $14 \cdot 0$ & $28 \cdot 0$ & $2 \cdot 0$ \\
Sulphate & $8 \cdot 2$ & $4 \cdot 0$ & $0 \cdot 5$ \\
Nitrate & $1 \cdot 5$ & $1 \cdot 8$ & $1 \cdot 2$ \\
Nitrite & $0 \cdot 003$ & $0 \cdot 006$ & $2 \cdot 0$ \\
Phosphate & $0 \cdot 06$ & $0 \cdot 6$ & $10 \cdot 0$ \\
Silicate & $26 \cdot 0$ & $13 \cdot 5$ & $0 \cdot 5$ \\
Carbonate & $100 \cdot 0$ & $207 \cdot 6$ & $2 \cdot 0$ \\
\hline Total & $220 \cdot 6$ & $413 \cdot 3$ & \\
\hline
\end{tabular}

TABLE 2.

\begin{tabular}{|l|c|c|c|}
\hline & Inflows & Tanganyika & Sea Water \\
\hline Chloride to sulphate & $1 \cdot 7-1$ & $\begin{array}{r}7-1 \\
0 \cdot 9-1\end{array}$ & $\begin{array}{c}7 \cdot 17-1 \\
2 \cdot 9-1\end{array}$ \\
\hline
\end{tabular}

the chemical composition of the Lake water. This may provide a partial explanation for the large number of 'endemic' species found in the Lake, many resembling marine types. It has been suggested that these may have evolved at a time when the Lake was shallower and more salt. But it seems certain that, before the Ruzizi flowed into the Lake, the concentration of salts was even less than at the present time, because this river now supplies the Lake with about a quarter of its incoming salts. It provides approximately 13 per cent of the inflowing water and its salt content is four times as high as that of the other inflows. Thus unless the Lake was reduced to a very small size during arid periods, the salt concentration was probably never very high.

Table 1 summarizes the present data on the chemical composition of the inflows and lake water of Tanganyika. The average values for the inflows are based on analyses made from nine inflows, including three major ones. The last column contains factors relating the concentration of the ions in the inflows to their concentration in the Lake. The more a particular ion has been utilized and removed from circulation, the lower the factor. In this connexion it should be noted that, if it were not for biological precipitation, the concentration of salts in the Lake would presumably by now have reached saturation point. It is evident that even soluble ions such as sodium and potassium and chloride are retained permanently in the bottom deposits.

Tanganyika possesses a marked degree of thermal stability, a very unusual feature in a tropical lake. Below $400 \mathrm{~m}$. the temperature of the water remains constant at $23 \cdot 1^{\circ} \mathrm{C}$. and appears to be unaffected by temperature changes or currents in the upper layers. A well-defined thermocline, at depths varying from $40 \mathrm{~m}$. to $100 \mathrm{~m}$. in different parts of the Lake at different seasons, is present for about eleven months of the year. Some exchange of water occurs between the epilimnion and the top $300 \mathrm{~m}$. of the hypolimnion, but normally no oxygen is found below the thermocline. The persistent nature of the thermocline is illustrated by the condition of the lake mud; below about $80 \mathrm{~m}$. it is of very fine consistency and black; above this level it is composed of larger particles and is grey in colour.

An important reason for the thermal stability of the Lake appears to be that the inflowing waters, which are cooler than the surface waters of the Lake, 
flow down the steep littoral region until they reach levels below the thermocline, thus maintaining the lower temperature of the deep water. A notable example of this is the Ruzizi. The formation of this inflow was probably an extremely significant event in the history of the Lake. Not only did it raise the level of the Lake and give Tanganyika an outlet, but also it probably very greatly reduced the productivity of the Lake by making its waters more stable. The abundance of empty shells on the beaches and the present apparent paucity of the molluscan fauna lends support to this theory. The oligotrophic nature of the Lake is due to its thermal stability, yet it is potentially very productive. Locked up in the hypolimnion are all the nutrient salts to support a prolific flora and fauna.

This storage of nutrient salts in the hypolimnion indicates a number of ways in which the productivity of this Lake and the surrounding agricultural areas might be increased. Any ageney which will affect mixing between the epi- and hypo-limnion will have an immediate beneficial effect on the Lake. This might be achieved mechanically in suitable localities or by irrigational schemes designed primarily to benefit agriculture. At the present time the inflows, rich in nutrient salts, are to a large extent unused, since they tend to enter the Lake at levels below the thermocline. If these inflows were used for irrigation, their temperature would be raised and their waters could then mix with the surface waters of the Lake, thus not only making their salts available, but also reducing to some extent the thermal stability of the Lake. In addition, the drainage of low-lying areas and the fertilizing of these areas with the rich bottom. deposits of the Lake would again benefit both agriculture and the fisheries, and would also improve the malarial situation. It is to be hoped that developments along these lines may one day be carried c ut.

The conditions obtaining in Tanganyika are ideal for studying the chemical factors which limit and control plankton development, since for considerable periods the thermocline is so well differentiated that the epilimnion is depleted of nutrient salts and the plankton so reduced that prolonged tow-netting yields only insignificant quantities. At other times seasonal variations in temperature, or changes in the strength and direction of the wind and internal wave (temperature seiche) effects, cause mixing between the surface and deep water which leads to considerable variations in the amounts of nutrient salts in the epilimnion. However, during the year, the temperature of the epilimnion varies little more than $3^{\circ} \mathrm{C}$. (from $23.5^{\circ} \mathrm{C}$. to $26 \cdot 5^{\circ} \mathrm{C}$.), and since the Lake lies close to the equator the seasonal variation in the amount of light falling on it is slight. Thus the effects of change in the chemical composition of the water can be studied in the absence of confusing alterations in ligh's and temperature. The exceptional suitability of this Lake for such investigations is apparent when one considers some of the difficulties met with in other tropical lakes and also in temperate lakes. In other tropical lakes thermal instability prevents complete utilization of the nutrient salts in the surface waters, so no estimate can be made of the limiting values of these salts; while in temperate lakes, which are thermally stable during the summer, the reduction in temperature and light during the winter, as well as the constant daily fluctuations in light, superimpose other factors which limit plankton development and prevent a proper evaluation of the effect of change in the composition of the water.
In Tanganyika changes in the hydrology of the Lake may at times be marked by very obvious changes in its biology. At the end of the cool season there is a well-recognized drift in the 'dagaa' fishery from the south end of the Lake towards the north end. The 'dagaa' are small plankton-feeding fish. At the same time the Tanganyika jelly-fish makes its appearance at the south end of the Lake and later is found farther and farther north. These events express in a most striking manner the effect of mixing between the surface and deeper waters of the Lake. At this season there is a gradual fall in the temperature of the surface .water, greatest towards the south, so that while it may be $25^{\circ} \mathrm{C}$. at the north end, it is only $23 \cdot 5^{\circ} \mathrm{C}$. at the south end. As a consequence the thermocline occurs at lower and lower levels and becomes less well defined, unti] in the shallower waters at the south end of the Lake it ceases to exist and very considerable mixing occurs with the deeper water rich in nutrient salts. There is then an immediate and abundant development of the plankton. The prevailing wind, which at this season is from the south, drifts this more productive water northwards. These happenings are brought to an end by the onset of the warmer weather, which is marked by a change in the wind, which now tends to blow from the north. This change in wind direction, however, has one further disturbing influence on the Lake; by changing the direction of the currents in the epilimnion, frictional disturbances arise at the level of the thermocline and bring about further mixing. From then on, more stable conditions arise, and continue, with minor changes, throughout the warm season.

Quite apart from biological studies on this Lake, which have scarcely been started, an immense amount of hydrolcgical work remains to be done and should yield results of quite exceptional interest and value; for they will not only help towards reaching an understanding of Tanganyika and its many problems, but will also advance appreciably our knowledge of the basic principles of hydrobiology.

A list of references to work on Tanganyika is given in a paper by me published in 1939 but not readily available (Int. Rev. Hydrobiol., 39; 1939), which also contains a more detailed account of the hydrology of Lake Tanganyika.

\section{OBITUARIES}

\section{Prof. E. S. Goodrich, F.R.S.}

EDwin STEPHEN Goodrich was born on June 21, 1868, at Weston-super-Mare and died at Oxford on January 6. He was brought up in France, spoke French like a Frenchman, and always remained a great admirer of that country. After returning to England he entered University College, London, in 1888, and it was while studying there as an art student at the Slade School that he heard some public lectures given by Ray Lankester and realized that zoology was his proper profession. He became assistant to Ray Lankester, and when the latter went to Oxford to become Linacre professor of zoology and comparative anatomy, Goodrich followed him. He entered Merton College as a commoner in 1892, and ultimately became a fellow and a professorial fellow of the same College, when he succeeded to the Linacre professorship in 1921. He always prided himself on his undivided allegiance to Merton, and it must have been a source of great satisfaction to him 